\title{
Construction of Natural Tourism Resource in ChangBai Mountain Under MOOC Idea
}

\author{
Xiu-li Li ${ }^{1, a^{*}}, \quad$ Zhe Xu', \\ ${ }^{1}$ JiLin Business And Technology College, ChangChun, China \\ 2JiLin Business And Technology College, ChangChun, China \\ alixiulibb@126.com, b120062231@qq.com \\ *Corresponding author Xiu-li Li
}

Key words: ChangBai Mountain ; natural resource; tourism

\begin{abstract}
In this paper, the author combines the new ideas of "MOOC concept" and "wisdom tourism", combined with the investigation of domestic tourism websites. To build a scientific human nature tourism information database for the purpose of giving visitors a better travel experience.
\end{abstract}

\section{Analysis on the Status of Tourism Information Database in China}

1.1 The Number of Sites but the Level is not Balanced Nowadays, tourism has become an important part of people's life style. With the rapid development of tourism, the domestic tourism websites are more and more popular. At the beginning of the new century in 2001 when the domestic tourism website has more than 5000. According to the different application functions can be divided into the following types, (Table 1).

Table 1. Classification of domestic tourism websites

\begin{tabular}{|l|l|l|l|}
\hline \multicolumn{1}{|c|}{ Travel booking } & \multicolumn{1}{|c|}{ Travel strategy } & \multicolumn{1}{c|}{ Travel information } & \multicolumn{1}{c|}{ facility of traveling } \\
\hline Where to go & $\begin{array}{l}\text { Ant cellular Travel } \\
\text { Network }\end{array}$ & Where is Ali & $\begin{array}{l}\text { National Tourism Administration of } \\
\text { the People's Republic of China }\end{array}$ \\
\hline ctrip & Poor travel network & Baidu Travel & China Travel Network \\
\hline Elong & Bread travel & Sina Travel Channel & Jilin Tourism Administration Network \\
\hline Tuniu & & Sohu Travel Channel & AirAsia website \\
\hline Donkey mother & & Tencent travel & \\
\hline Same way network & & Taobao travel & \\
\hline
\end{tabular}

The hotel is scheduled to travel to provide visitors with a ticket + Hotel + ticket discount, in favor of tourism e-commerce, but these sites pay more attention to the hotel and transportation and other static resources, so the same information is very common. UGC (User Generated Content) is used Travel Raiders website, Visitors are free to share their travel experience and experience and recommend more friends to help them make travel plans. Highly interactive, equivalent to a platform for tourism and social networking, online travel industry breakthrough.

1.2 Travel Bookings Continue to Grow The author according to the Alexa and the National Bureau of statistics data analysis, on the domestic tourism web site of the per capita amount of view summarized as below (Fig.1).

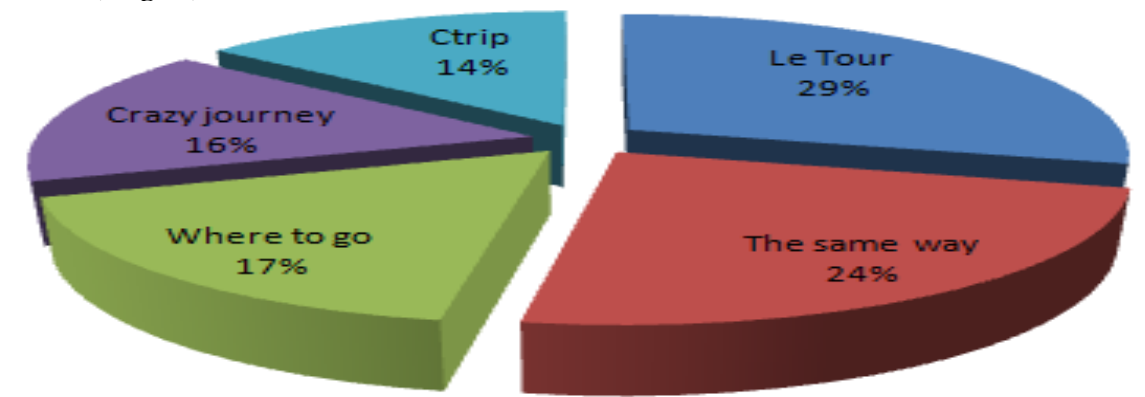

Fig.1. daily visits per day of domestic tourism websites 
Statistics show that as of 2016 June, travel booking market has been the most used type of website visitors, 2012 type of users in the online travel booking behavior on the basis of China Internet Network Information Center released the date of the "investigation report" shows that as of June 2012, China's online travel booking users reached 42 million 580 thousand people, in recent years the growth of the rate is relatively slow, but overall steady growth ${ }^{[1]}$.

1.3 Extensive Service Function Is Not Deep According to China's online travel market segments around the size of the structure change forecast, we can clearly see the tourists have more love to choose self-help rather than travel with the group explains the popularity of the Internet and the information asymmetry improved, tourists from the herd to tourism has been transformed into life experience body. People's ability to produce data has also been strengthened, the majority of tourists rely on the network, smart mobile terminals, APP software to serve their travel plans. The current tourism website in addition to traditional services such as: information services, booking services and customer management, including traffic search, travel experience, map positioning, online consulting and other interactive information services.

\section{Using MOOC Concept to Build "Wisdom Travel" Information Database}

MOOC is a large-scale network open course, he used a variety of video, community and other educational model will be the world's teaching and learning through the internet. MOOC is a new mode of education is the knowledge innovation platform, learners create diverse perspectives on this platform, dynamic processing to stimulate more diverse knowledge and meridians ${ }^{[2]}$, but also very good driver MOOC output more rich knowledge base.

MOOC has the characteristics of large scale, easy access, rapid propagation, individuation and strong interaction, so it is a powerful supplement to promote the natural resources of Changbai Mountain to construct the natural tourism information base of Changbai Mountain.

(1) to collect the natural condition of Changbai Mountain each devoted to upload, the characteristics of natural resources a Landrace, gradually formed a large number of learning resources, learners to watch and participate in more traditional teaching methods have a relatively large increase is no longer limited by space. MOOC uses data mining and artificial intelligence technology in the background, from a variety of angles to explore the behavior of the learners to analyze the interest and the law of Changbai Mountain. Dynamically change the orientation and service support of the students according to the needs of the learners.

(2) because MOOC advocates sharing, it is an inherent feature of the Internet age to gain access. Changbai Mountain's natural tourism resources, tourism routes, such as the characteristics of the landscape, such as the production of small video which makes it convenient for tourists to use mobile terminals anytime, anywhere to watch. The visitors are free to interact with each other on the platform and share the experience of travel, and so on.

(3) intelligent era, the application of new media is recognized. It can be said that everyone is the media, from time to time in the dissemination. MOOC learning resources generated and spread through the Internet space, visitors through social media software to create their own social circle and knowledge circle. The content of the natural resources in Changbai Mountain is not pushed to tourists, but tourists into the information library. And tourists are also involved in the creation of Changbai Mountain tourism, the formation of the spread between tourists and tourists, and enhance the penetration of Changbai Mountain tourism ${ }^{[3]}$.

(4) the most important value is to make a travel plan for the purpose and level of consumption. In the current domestic tourism website, there is no basis for the interest of tourists and the level of tourism planning path function. Therefore, Changbai Mountain natural tourism information database according to the background of MOOC provide visitors personal files and travel behavior, using collaborative filtering techniques to recommend their potential to accept the hotel price, attractions such as a series of plans to travel to the tourists ${ }^{[4]}$.

(5) interactivity is an important feature of MOOC distinction and traditional open class. Arrangements for the discussion of the module in the video, visitors can communicate around a landscape, sharing feelings. Visitors can also participate in various activities organized by the 
Changbai Mountain natural tourism information database. As a supplementary form of MOOC, you can set up a professional customer service team, collect fees and limit the number of people. This answer staff can better understand the needs of tourists, providing detailed and specific travel support, but also more interactive.

\section{Summary}

Make full use of modern information technology means to build a more comprehensive and easy to use natural resources tourism information base in Changbai Mountain to meet the needs of more tourists on Intelligent services. And the combination of MOOC concept is an idea to upgrade the tourism experience of tourists, in the future research, the author also need to deepen and explore the theme of the study.

\section{Acknowledgements}

This paper is one of the research results of "Research on the construction of Changbai Mountain tourism resources information database under the concept of MOOC" which is Jilin business school in 2016 the humanities and Social Sciences project(Project No.: 001th, 2016).

\section{Reference}

[1] Zhu. Study on online booking behavior of tourism website users [D]. Shanghai: East China Normal University, 2014:22-23.

[2] Wang Yonggu, Zhang Qing. MOOC: characteristics and learning mechanism [J]. education research, 2014( 9):113-114.

[3] David Glance, et al. The Pedagogical Foundations of Massive Open Online Courses[J].First Monday,2013(5).

[4] Inge de Waard, et al. Using m Learning and MOOCs to Understand Chaos,Emergence, and Complexity in Education[J].International Review of Research in Open and Distance Learning,2011(7). 